\title{
Evaluating student allocation in the Portuguese public higher education system
}

\author{
Miguel Portela $\cdot$ Nelson Areal $\cdot$ Carla Sá $\cdot$ Fernando Alexandre $\cdot$ \\ João Cerejeira $\cdot$ Ana Carvalho $\cdot$ Artur Rodrigues
}

Published online: 23 September 2007

(C) Springer Science+Business Media B.V. 2007

\begin{abstract}
This paper characterizes and evaluates the student allocation in the Portuguese public higher education system. It describes the supply and demand sides of the system by looking at the numerus clausus across areas of study and institutions, institutions' degree of diversity, and performance and adjustment indicators based on students' revealed preferences. Performance indicators quantify the adequacy between demand and supply, across institutions and fields of study, and gauge the performance of public higher education institutions in the competition for candidates. Adjustment indicators allow us to predict the potential impact of changes in higher education regulations on student allocation and its stability. According to these indicators, such changes could result in an expansion for some institutions and fields of study, whereas other institutions might face a reduction.
\end{abstract}

Keywords Demand $\cdot$ Higher education market $\cdot$ Regulation $\cdot$ Supply

\section{Introduction}

During the last quarter of the twentieth century, the European higher education sector witnessed an unprecedented expansion with recognised impacts on participation rates. Such increase in participation has been accompanied by large investments on the supply side, and generated, in several countries, an increasing competition for students. At present,

M. Portela

Universidade do Minho, NIPE and IZA, Braga, Portugal

N. Areal · A. Carvalho - A. Rodrigues

Universidade do Minho and NEGE, Braga, Portugal

C. Sá $(\bowtie)$

Universidade do Minho and NIPE and CIPES, Braga, Portugal

e-mail: cangelica@eeg.uminho.pt

F. Alexandre $\cdot$ J. Cerejeira

Universidade do Minho and NIPE, Braga, Portugal 
the Lisbon Strategy and the increasing international competition from the US, China and India, have made the evaluation of the higher education sectors and their reform a hot topic across Europe (see, for example, van der Ploeg and Veugelers 2007).

In this context, many countries' governments have been forced to evaluate the performance of their higher education systems, which in turn has brought the role of the state and the implementation of marketisation policies in higher education back into public discussion. Several recent studies have reflected these concerns. Rhoades and Slaughter (2004) and Geiger (2004) analyze the impact of market-like behavior in the American higher education system. Teixeira et al. (2004) discuss the implications of introducing market-oriented mechanisms for the functioning of higher education systems by looking at the experience of several countries.

The recent trends in the Portuguese higher education system have followed the general tendency for expansion. Places available have steadily increased over time, following the increase in the number of candidates, with the maximum number of applicants being achieved in 1995/96. The Portuguese system has moved from excess demand to a situation of demand closer to supply, with excess supply in some of the most recent school years. A recent study by Teixeira et al. (2004) documents very well the status quo regarding effective market regulation, in the present framework of increasing competition for students.

However, the imbalances of the market remain to be quantified. In particular, the matching between demand and supply has to be analysed. In this paper we focus on the Portuguese public higher education system in terms of the student allocation across institutions and fields of study. ${ }^{1}$ We describe demand and supply sides of the system using data on numerus clausus by institution and by area of study, and on candidates' revealed preferences for the period 2003/2004 to 2006/2007. We compute measures for student allocation across higher education institutions and fields of study, namely: occupation rates, first option-admitted student ratio, a demand pressure index, average preference rank, and the mean grade point average of the pool of admitted students. These indicators allow for the analysis of the adequacy between the higher education supply and demand across institutions and fields of study. We argue that those indicators gauge the performance of public higher education institutions in the competition for candidates. After describing the allocation of students across institutions and fields of study, we compute two indicators that allow for the identification of the locus of rigidity in the Portuguese higher education system, and for the indication of the direction of the adjustment in institutions and fields of study supply if more flexibility was introduced in the system.

The paper proceeds as follows. The higher education system in Portugal is the focus of section "The Portuguese higher education system: institutions and regulation". Section "The higher education market for undergraduate students" provides a description of both demand and supply sides of the public higher education system. In section "Indicators of student allocation in public higher education institutions", we introduce and compute some indicators which allow us to describe the allocation of students across public higher education institutions and fields of study and the potential adjustment of supply to changes in higher education regulations. Finally, section "Concluding remarks" concludes and points out possible directions for future research.

\footnotetext{
${ }^{1}$ It is important to note that there is no single higher education market, instead there is a multitude of markets: namely, a market for students, for researchers, for lecturers, for scholarships and grants, for graduates, among others (Jongbloed 2003). In the present study, we concentrate on a specific market: the market for undergraduate students, which will be the one referred to when speaking of market.
} 


\section{The Portuguese higher education system: institutions and regulation}

The Portuguese higher education system is a binary system, with universities and polytechnics as the main providers. The distinctive feature between universities and polytechnics is the focus on research: polytechnics are not expected to conduct fundamental research, and should offer vocationally or professionally oriented study programmes. The system consists of 27 universities, 40 university schools, 17 polytechnic institutes and 76 polytechnic schools, making a total of 160 units, including both private and public higher education providers. The latter comprises 14 universities, 15 polytechnic institutes, 9 nursing schools and 2 other polytechnic schools. ${ }^{2}$ The public polytechnic network is, in part, a result of government's aim of assuring regional diversity of the higher education network and equity in access to higher education.

A large number of institutions, for a small number of participants, is a key feature of the Portuguese higher education network (OECD 2006). After a period of extraordinary growth in the number of candidates and registered students in the tertiary education system, since 2003/2004 total enrolments have decreased, resulting in a reduction in the occupation rate from $95.4 \%$ to $82.1 \%$ in 2005/2006 (OCES 2007: 15). However, this trend has affected public higher education institutions and fields of study unevenly. Furthermore, the Ministry of Sicence, Technology and Higher Education (MCTES, Ministério da Ciência, Tecnologia e Ensino Superior) has been in charge of the higher education sector and regulates it by controlling access conditions, favouring accreditation and quality assessment of study programmes and institutions, and funding both institutions and students.

Accreditation and quality assessment are among the instruments available to regulate the public higher education system. However, the approval of new study programmes and degrees is just a bureaucratic procedure; that is, it does not depend on an evaluation or accreditation process: only formal inconsistency concerning the duration or the total number of credits can lead to a refusal of universities' new degrees. Public polytechnics' study programmes need a formal approval by the MCTES, based on technical and scientific report. $^{3}$

The MCTES regulates access to the higher education system through admission policies as well. Currently, access to public higher education works through a national competition based on students' revealed preferences and their grade point average, which is a weighted average of their marks in upper secondary education and in national examinations. ${ }^{4} \mathrm{Stu}-$ dents have to rank a maximum of six study programme/institution pairs, from the most preferred (the first one) to the least preferred (the last one) alternative. A nationwide competition involving all candidates and places follows. Admission policies are crucial for the number of candidates and student enrolments in higher education, as changes in access conditions may result in great changes in the number of candidates. 5

Public funding of higher education institutions is guaranteed through several channels: a funding formula, based on which direct funding of institutions is defined; contracts for specific activities; the funding of social support services, mainly student grants, meals and

\footnotetext{
2 According to the MCTES (2006), enrolments in the private subsystem represent about $26 \%$ of the total enrolments in graduate and pos-graduate studies.

3 New study programmes in private institutions are subject to very strict requirements, and institutions must be officially recognised in order to award degrees.

${ }^{4}$ In the private sector there is a decentralized application system.

5 For example, the reintroduction of minimum marks (95/200), in 2004, coincided with a reduction of candidates and enrolments (MCTES 2006).
} 
accommodation; and research funds. Given the weight of student enrolment in the funding formula, the recent decline in overall enrolments in tertiary education poses a problem for the financial sustainability of higher education institutions. However, the share of tuition fees revenue in higher education institutions budgets has been increasing, reaching $17 \%$ in 2006, which is close to the OECD average of 19\% (OECD 2006: 81). Institutions are not entirely free to set the tuition fees, as minimum and maximum limits are imposed by law. For instance in 2003/2004, those limits were $€ 450$ and $€ 850$, respectively. This implies that fees may vary across institutions and study programmes. ${ }^{6}$ For example, fees in Polytechnics are, on average, lower than fees in universities.

Another instrument used by the MCTES to regulate the higher education system is the numerus clausus, which defines the maximum number of students for each study programme in both public and private sectors. Numerus clausus works as a restriction on the supply side of the system, affecting the size and composition of the tertiary education sector. According to OECD (2006: 26), those restrictions have been settled "without a formal national higher education planning framework." Numerus clausus translates into rigidity in the system, which has implied a sluggish adjustment of the supply to changes in demand, visible in the conspicuous imbalances between demand and supply, which we will characterize in the next sections.

\section{The higher education market for undergraduate students}

This section describes higher education supply and demand. As explained above, the allocation of candidates to institutions and study programmes is the result of a nationwide competition and it is based on their stated preferences. The analysis is then based on a data set consisting of those revealed preferences. We will focus on the public sector, as it is governed by a more homogeneous set of rules and benefits from a centralized application process. Furthermore, the data are publicly available on a website created for that purpose by the MCTES. ${ }^{7}$ The data available include information on institution/ programme pairs, from 2003/2004 to 2006/2007, namely: number of applicants placing each pair among their preferences, total number of times a given pair is the first option, the mean of the grade point average of students who applied for each study programme and who were admitted to it.

\section{Supply side}

We look at the supply side of the higher education market, by analysing the distribution of numerus clausus, as well as programme diversity. The capacity of the Portuguese higher education system is decided on a yearly basis by the MCTES, which approves the distribution of numerus clausus across areas of study proposed by each institution of higher education.

Table 1 shows the distribution of numerus clausus by institution and field of study, in 2006, where heterogeneity across institutions is visible. Several important results emerge from this table. Firstly, the university sector takes almost $60 \%$ of the total capacity,

\footnotetext{
${ }^{6}$ Note that fees represent about $22 \%$ and $18 \%$ of the total monthly expenditure of university and polytechnic students (MCTES 2006).

7 The information is available at: http://www.acessoensinosuperior.pt.
} 
Table 1 Distribution of places by institution and area of study, 2006

\begin{tabular}{|c|c|c|c|c|c|c|c|c|c|c|c|c|}
\hline Institution & agric & $\operatorname{arch}$ & natsc & lawsoc & eco & sparts & educ & hum & health & tec & Total & Diversity \\
\hline ESuperiores & & & & 60 & 185 & & & & 1,003 & 50 & 1,298 & \\
\hline PI Beja & 115 & 30 & 25 & 165 & 50 & 25 & 55 & & 70 & 91 & 626 & 0.872 \\
\hline PI Bragança & 198 & 40 & & 195 & 250 & 60 & 205 & 25 & 220 & 530 & 1,723 & 0.834 \\
\hline $\begin{array}{c}\text { PI Castelo } \\
\text { Branco }\end{array}$ & 42 & 100 & & 224 & 130 & & 80 & 25 & 150 & 224 & 975 & 0.826 \\
\hline PI Cávado\&Ave & & 81 & & 25 & 135 & & & & & 85 & 326 & 0.547 \\
\hline PI Coimbra & 180 & 70 & 30 & 295 & 300 & 30 & 95 & 20 & 180 & 520 & 1,720 & 0.836 \\
\hline PI Guarda & 30 & 25 & & 234 & 160 & 35 & 70 & 30 & 110 & 105 & 799 & 0.838 \\
\hline PI Leiria & 60 & 160 & 90 & 460 & 215 & 85 & 95 & 35 & 120 & 316 & 1,636 & 0.886 \\
\hline PI Lisbon & & 55 & 35 & 202 & 333 & & 166 & & 385 & 720 & 1,896 & 0.706 \\
\hline PI Oporto & & 40 & 45 & 315 & 500 & & 154 & 65 & 410 & 865 & 2,394 & 0.731 \\
\hline PI Portalegre & 80 & 69 & & 209 & 72 & & 55 & 72 & 77 & 96 & 730 & 0.860 \\
\hline PI Santarém & 50 & 20 & & 135 & 170 & 154 & 90 & & 90 & 85 & 794 & 0.846 \\
\hline PI Setúbal & 25 & 25 & & 142 & 302 & 20 & 78 & 16 & 109 & 482 & 1,199 & 0.716 \\
\hline PI Tomar & 35 & 172 & & 35 & 210 & & & 35 & & 242 & 729 & 0.653 \\
\hline $\begin{array}{l}\text { PI Viana } \\
\text { do Castelo }\end{array}$ & 99 & 70 & & 60 & 66 & 30 & 105 & & 66 & 210 & 706 & 0.839 \\
\hline PI Viseu & 223 & 60 & & 302 & 200 & & 185 & 30 & 120 & 265 & 1,385 & 0.835 \\
\hline $\begin{array}{l}\text { Total } \\
\quad \text { Polytechnic }\end{array}$ & 1,137 & 1,017 & 225 & 3,058 & 3,278 & 439 & 1,433 & 353 & 3,110 & 4,886 & 18,936 & 0.860 \\
\hline ISCTE & & 35 & & 334 & 361 & & & 35 & & 126 & 891 & 0.549 \\
\hline Technical U & 260 & 343 & 110 & 343 & 498 & 154 & & & 70 & 1,355 & 3,133 & 0.736 \\
\hline U Algarve & 90 & 120 & 145 & 315 & 315 & 30 & 135 & 105 & 225 & 275 & 1,755 & 0.932 \\
\hline U Aveiro & 45 & 85 & 272 & 167 & 365 & 30 & 75 & 167 & 158 & 627 & 1,991 & 0.857 \\
\hline U Azores & 22 & 25 & 40 & 178 & 70 & & 40 & 20 & 45 & 85 & 525 & 0.841 \\
\hline U Beira Interior & & 170 & 145 & 165 & 110 & 100 & 21 & 70 & 190 & 240 & 1,211 & 0.900 \\
\hline U Coimbra & 40 & 60 & 285 & 870 & 275 & 95 & 120 & 269 & 449 & 604 & 3,067 & 0.859 \\
\hline U Évora & 80 & 110 & 167 & 165 & 90 & 50 & 60 & 80 & 76 & 95 & 973 & 0.969 \\
\hline U Lisbon & & 260 & 685 & 920 & & 40 & 90 & 741 & 653 & 245 & 3,634 & 0.785 \\
\hline U Madeira & & 30 & 50 & 114 & 55 & 20 & 60 & 25 & 73 & 120 & 547 & 0.887 \\
\hline U Minho & & 100 & 272 & 427 & 172 & & 111 & 230 & 194 & 718 & 2,224 & 0.813 \\
\hline U Nova & 85 & 55 & 205 & 375 & 465 & 20 & & 295 & 200 & 755 & 2,455 & 0.812 \\
\hline U Oporto & 120 & 313 & 485 & 530 & 330 & 110 & 55 & 365 & 730 & 900 & 3,938 & 0.900 \\
\hline UTAD & 143 & 25 & 187 & 338 & 85 & 95 & 100 & 45 & 72 & 210 & 1,300 & 0.906 \\
\hline $\begin{array}{l}\text { Total } \\
\text { University }\end{array}$ & 885 & 1,731 & 3,048 & 5,241 & 3,191 & 744 & 867 & 2,447 & 3,135 & 6,355 & 27,644 & 0.911 \\
\hline Total & 2,022 & 2,748 & 3,273 & 8,299 & 6,469 & 1,183 & 2,300 & 2,800 & 6,245 & 11,241 & 46,580 & 0.910 \\
\hline
\end{tabular}

Notes: 1 . The number of places is computed as the maximum number of vacancies among the values announced for the two phases

2. The study areas in columns are the following: agriculture (agric), architecture (arch), natural sciences (natsc), law and social sciences (lawsoc), economics (eco), sports and arts (sparts), education (educ), humanities (hum), health (health), and technology (tec)

3. ESuperiores is the abbreviation for Escolas Superiores, which include nine nursing schools, a nautic school and a hotel management school. Because all these schools have a very specialized supply, we opted for collapsing the vacancies

4. The diversity index is computed as in Eq. 1, for each higher education institution. It does not apply to the set of schools under the name ESuperiores. Note that nursing schools offer study programs on health only, implying that the diversity index takes the value 0 for most institutions in that set

5. U stands for University and PI stands for Polytechnic Institute 
measured as the number of places. That is, there are almost 28,000 places for new students to attend university, and about 19,000 to attend a polytechnic. Secondly, the institutions with the largest capacity belong to the university sector. Furthermore, the biggest (and also the oldest) four universities (Coimbra, Lisbon, Oporto and the Technical University) take 13,772 places, that is, about $29.5 \%$ of the total places available in the public higher education subsystem. Looking at the polytechnic sector numerus clausus, big institutions, like the one in Oporto, coexist with small ones (e.g., PI Cávado\&Ave). Also in the university sector, the University of Oporto, the biggest institution, is almost 8 times bigger than the smallest one (University of Azores).

According to Huisman et al. (2000), diversity is among the instruments available to governments aiming at shaping the demand for higher education. For instance, increasing diversity enlarges the range of choices offered to students, and consequently it will make higher education accessible to more people and will allow a better fit between supply and demand. For the analysis that follows we look at study programme diversity. The total number of places by institution and field of study is used to compute a Shannon-Wiener diversity index of each institutional study offer ${ }^{8}$

$$
\text { Diversity }_{s}=-\sum_{m=1}^{M} p_{m} \log p_{m},
$$

where $M=10$ is the number of areas of study offered by Portuguese public higher education institutions; and $p_{m}$ is the proportion of study programme type $m$ in a given institution measured by total number of places.

Programme diversity index values, by higher education institution, by subsystem, and for the entire higher education system, are shown in the last column of Table 1. The overall diversity is quite high (0.910). When comparing subsystems, the university subsystem reveals a higher diversity than the polytechnic subsystem. This does not come as a surprise; it follows from the starting up conditions imposed by the Portuguese legislation. ${ }^{9}$ The universities of Algarve and Évora are among those at the top of institutions offering the most diverse set of studies. It might be the case that since they are located in quite remote areas, with no competition from nearby universities, they strategically opt for offering study programmes in all fields of study, with a small number of places, in order to capture local demand. The ISCTE ${ }^{10}$, University of Lisbon and the Technical University, all located in Lisbon, present the lowest diversity. In fact, Lisbon numbers four universities, which might allow for some degree of specialization, with no risk of losing students to other regions.

\section{Demand side}

Since the mid 1990s, demand for higher education has been affected by several factors, namely: changes in demography and the reintroduction of national exams and minimum

\footnotetext{
8 This index is used in Brose (2003), who took it from Magurran, in his work dated from 1988 on ecological diversity measurement.

9 The creation of a new university requires a minimum of 8 study programmes in at least three different areas of study, whereas a polytechnic can be created with just two study programmes, which may belong to the same area of study (Simão et al. 2004).

${ }^{10}$ ISCTE is a specialised school, where most studies are concentrated in two fields: Law and Social Sciences, and Economics and Management.
} 
Table 2 Proportion of students with consistent choice sets regarding the higher education institution type, 2003-2006

\begin{tabular}{llllll}
\hline Type of institution & $2003 / 2004$ & $2004 / 2005$ & $2005 / 2006$ & $2006 / 2007$ & Total \\
\hline Non-University & 0.332 & 0.333 & 0.265 & 0.251 & 0.296 \\
University & 0.477 & 0.486 & 0.486 & 0.458 & 0.476 \\
\hline
\end{tabular}

Note: Proportions in this table are computed as the number of individuals with only that type of institution in the choice set to the total number of individuals who have at least one institution of that type in the choice set

marks as entrance conditions (MCTES 2006; OECD 2006). All these issues have shaped students' preferences. On top of that, peer effects are highly probable and individuals are very likely to influence their colleagues and friends through their revealed preferences (Sá 2006). These reasons justify the analysis of the demand in the undergraduate student market being based on students' revealed preferences.

Two facets of the demand for higher education are analysed. Firstly, we will study the consistency of students' preferences. As explained in section "The Portuguese higher education system: institutions and regulation", each candidate's choice set has up to six choices, ranked from the most to the least preferred option. This means that the choice sets might vary significantly across students. The choice sets of some students are only composed of university institutions, while others are only of polytechnics; a mixture of both being also possible. In order to analyse how consistent student choice sets are, a choice set is defined as consistent when it includes only identical choices. ${ }^{11}$

Regarding the choice of type of higher education institution choice, it is interesting to note that the proportion of students whose choice set only contains university options is higher than that of students with only polytechnics in their choice set (see Table 2). It is evident that the proportion of students with just universities in their choice sets is more stable than that of students with a polytechnic choice set over the period under analysis. The biggest decrease in the proportion of students with a polytechnic choice set occurred between 2004/2005 and 2005/2006, when it decreased about 6 percentage points. ${ }^{12}$

Such rates of consistency are not evenly distributed across higher education institutions. This is possibly because distance constraints apply to student choices, which confirms the well-known negative impact of distance on student higher education decisions (see, for instance, Sá et al. 2004, for the case of Dutch students). According to Table 3, universities in Madeira, the Algarve and the Azores, located in more remote areas, show the highest consistency rates for the overall period between 2003 and 2007 (30.3\%, 16.2\% and 13.1\%, respectively). The opposite result is found for the four universities located in Lisbon, which show quite low consistency rates: $3.4 \%$ for the University Nova of Lisbon, $4.6 \%$ for the ISCTE, $6.3 \%$ for the University of Lisbon, and $8.3 \%$ for the Technical University. However, when consistency regarding the region is analysed, Lisbon takes the biggest share of students that consistently choose to study in that region (about 43\%). This implies that a considerable number of students have a strong preference for studying in Lisbon, which is obviously justified given its diversity in the study programme supply. ${ }^{13}$

\footnotetext{
11 Consistency, however, should not be understood by its usual meaning in Microeconomic theory.

12 An individual has a polytechnic choice set if his choice set only contains polytechnic schools.

13 More detailed data on regional consistency is shown in Portela et al. (2007).
} 
Table 3 Proportion of students with consistent choice sets regarding the higher education institution, 20032006

\begin{tabular}{|c|c|c|c|c|c|}
\hline Institution & $2003 / 2004$ & $2004 / 2005$ & $2005 / 2006$ & $2006 / 2007$ & Total \\
\hline PI Beja & 0.082 & 0.087 & 0.073 & 0.049 & 0.074 \\
\hline PI Bragança & 0.073 & 0.067 & 0.048 & 0.046 & 0.059 \\
\hline PI Castelo Branco & 0.040 & 0.042 & 0.029 & 0.033 & 0.036 \\
\hline PI Cávado\&Ave & 0.156 & 0.116 & 0.083 & 0.048 & 0.094 \\
\hline PI Coimbra & 0.064 & 0.055 & 0.039 & 0.045 & 0.051 \\
\hline PI Guarda & 0.032 & 0.034 & 0.020 & 0.020 & 0.027 \\
\hline PI Leiria & 0.087 & 0.084 & 0.073 & 0.078 & 0.081 \\
\hline PI Lisbon & 0.093 & 0.100 & 0.077 & 0.072 & 0.085 \\
\hline PI Oporto & 0.141 & 0.151 & 0.110 & 0.112 & 0.128 \\
\hline PI Portalegre & 0.046 & 0.041 & 0.038 & 0.031 & 0.040 \\
\hline PI Santarém & 0.065 & 0.063 & 0.043 & 0.046 & 0.055 \\
\hline PI Setúbal & 0.158 & 0.147 & 0.089 & 0.080 & 0.122 \\
\hline PI Tomar & 0.079 & 0.087 & 0.050 & 0.028 & 0.065 \\
\hline PI Viana do Castelo & 0.066 & 0.077 & 0.040 & 0.045 & 0.058 \\
\hline PI Viseu & 0.088 & 0.077 & 0.062 & 0.070 & 0.075 \\
\hline ISCTE & 0.048 & 0.041 & 0.055 & 0.040 & 0.046 \\
\hline Technical U & 0.084 & 0.086 & 0.090 & 0.072 & 0.083 \\
\hline U Algarve & 0.178 & 0.172 & 0.159 & 0.144 & 0.162 \\
\hline U Aveiro & 0.068 & 0.071 & 0.068 & 0.059 & 0.066 \\
\hline U Azores & 0.186 & 0.131 & 0.099 & 0.126 & 0.131 \\
\hline U Beira Interior & 0.031 & 0.035 & 0.021 & 0.021 & 0.027 \\
\hline U Coimbra & 0.067 & 0.064 & 0.057 & 0.057 & 0.061 \\
\hline U Évora & 0.045 & 0.043 & 0.037 & 0.040 & 0.041 \\
\hline U Lisbon & 0.069 & 0.067 & 0.068 & 0.050 & 0.063 \\
\hline U Madeira & 0.350 & 0.290 & 0.301 & 0.294 & 0.303 \\
\hline U Minho & 0.085 & 0.084 & 0.090 & 0.086 & 0.086 \\
\hline U Nova & 0.032 & 0.037 & 0.033 & 0.034 & 0.034 \\
\hline U Oporto & 0.105 & 0.111 & 0.106 & 0.104 & 0.106 \\
\hline UTAD & 0.046 & 0.051 & 0.035 & 0.043 & 0.044 \\
\hline
\end{tabular}

Notes: 1. Proportions in this table are computed as the total number of students with only that institution in the choice set to the total number of students that have placed that institution among their choices, at least once. Most other schools in the polytechnic sector, namely nursing schools offer only one study programme, which does not allow for the computation of the consistency rate

2. See footnote 5 , Table 1

The other issue to be analysed on the demand side is that of students' preferences regarding institutions. The demand faced by each institution can be analysed by counting the number of students who have included it in their choice set, no matter its rank, which we call hits.

Table 4 shows the distribution of the total number of hits, by higher education institution and field of study, in 2006. Total demand for university education is higher than total demand for polytechnic education. In both subsystems, the institutions in Oporto are at the top of the demand. As expected, universities located in remote areas, such as those in the 
Table 4 Distribution of total hits by institution and area of study, 2006

\begin{tabular}{|c|c|c|c|c|c|c|c|c|c|c|c|}
\hline Institution & agric & $\operatorname{arch}$ & natsc & lawsoc & eco & sparts & educ & hum & health & tec & Total \\
\hline Esuperiores & & & & 454 & 1,499 & & & & 8,489 & 50 & 10,492 \\
\hline PI Beja & 378 & 85 & 132 & 638 & 175 & 55 & 227 & & 611 & 200 & 2,501 \\
\hline PI Bragança & 733 & 78 & & 668 & 517 & 142 & 740 & 62 & 2,394 & 1,090 & 6,424 \\
\hline $\begin{array}{c}\text { PI Castelo } \\
\text { Branco }\end{array}$ & 270 & 631 & & 874 & 625 & & 346 & 103 & 1,658 & 868 & 5,375 \\
\hline PI Cávado\&Ave & & 417 & & 399 & 1,007 & & & & & 202 & 2,025 \\
\hline PI Coimbra & 1,151 & 599 & 127 & 1,580 & 1,391 & 109 & 645 & 223 & 1,600 & 2,942 & 10,367 \\
\hline PI Guarda & 121 & 143 & & 966 & 711 & 213 & 448 & 132 & 1,350 & 225 & 4,309 \\
\hline PI Leiria & 285 & 825 & 469 & 3,049 & 946 & 313 & 293 & 39 & 1,483 & 1,122 & 8,824 \\
\hline PI Lisboa & & 294 & 172 & 4,020 & 2,024 & & 774 & & 3,382 & 2,524 & 13,190 \\
\hline PI Portalegre & 323 & 198 & & 1,015 & 133 & & 164 & 191 & 1,052 & 169 & 3,245 \\
\hline PI Oporto & & 45 & 161 & 3,559 & 2,822 & & 327 & 88 & 5,006 & 4,017 & 16,025 \\
\hline PI Sar & 205 & 117 & & 917 & 579 & 952 & 360 & & 55 & 244 & 29 \\
\hline PI Setúbal & 46 & 71 & & 841 & 1,176 & 39 & 631 & 3 & 1,493 & 1,306 & 5,606 \\
\hline PI Tomar & 163 & 622 & & 138 & 495 & & & 33 & & 422 & 1,873 \\
\hline $\begin{array}{c}\text { PI Viana do } \\
\text { Castelo }\end{array}$ & 555 & 353 & & 394 & 315 & 173 & 330 & & 433 & 710 & 3,263 \\
\hline PI Viseu & 750 & 179 & & 1,569 & 675 & & 642 & 60 & 1,257 & 707 & 5,839 \\
\hline $\begin{array}{l}\text { Total } \\
\quad \text { Polytechnic }\end{array}$ & 4,980 & 4,657 & 1,061 & 21,081 & 15,090 & 1996 & 5,927 & 934 & 31,363 & 16,798 & 887 \\
\hline ISCTE & & 514 & & 2,432 & 2,796 & & & 180 & & 985 & 6,907 \\
\hline Technical U & 872 & 3,420 & 734 & 2,746 & 3,025 & 497 & & & 1,721 & 4,826 & 17,841 \\
\hline U Algarve & 327 & 544 & 669 & 1,660 & 1,390 & 80 & 399 & 280 & 2,307 & 726 & 8,382 \\
\hline U Aveiro & 192 & 585 & 2,128 & 2,220 & 2,694 & 36 & 590 & 799 & 2,199 & 4,579 & 16,022 \\
\hline U Azores & 70 & 62 & 137 & 808 & 175 & & 38 & 4 & 73 & 153 & 2,225 \\
\hline U Beira Interior & & 993 & 813 & 1,209 & 547 & 551 & 16 & 121 & 3,479 & 336 & 8,065 \\
\hline U Coimbra & 163 & 245 & 1,803 & 6,216 & 1,776 & 982 & 581 & 818 & 3,730 & 2,019 & 18,333 \\
\hline U Évora & 478 & 655 & 451 & 1,163 & 577 & 254 & 538 & 150 & 875 & 274 & 5,415 \\
\hline U Lisbon & & 1,865 & 2,132 & 3,136 & & 218 & 240 & 1,610 & 3,865 & 1,337 & 14,403 \\
\hline U Madeira & & 52 & 51 & 997 & 283 & 40 & 155 & 51 & 696 & 113 & 2,438 \\
\hline U Minho & & 427 & 706 & 2,513 & 1,228 & & 786 & 917 & 1,951 & 3,616 & 12,144 \\
\hline U Nova & 257 & 141 & 1,488 & 2,684 & 2,512 & 65 & & 1,104 & 2,875 & 3,225 & 14,351 \\
\hline U Oporto & 784 & 1,468 & 3,395 & 3,433 & 986 & 587 & 672 & 2,003 & 5,418 & 4,171 & 22,917 \\
\hline UTAD & 636 & 148 & 1,751 & 1,971 & 288 & 599 & 244 & 109 & 717 & 627 & 7,090 \\
\hline Total University & 3,779 & 11,119 & 16,258 & 33,188 & 18,277 & 3,909 & 4,259 & 8,189 & 30,568 & 26,987 & 156,533 \\
\hline
\end{tabular}

Note: 1 . Hits are the total number of choice sets including a study programme in a field of study and a given higher education institution

2. See footnotes 2 and 5 , Table 1

islands of Madeira and Azores, as well as Évora, face a lower demand. It is also interesting to note that Health is the most chosen field in the polytechnic subsystem, whereas Humanities is the least chosen. In the university subsystem, Law and Social Science studies receive the highest number of hits, while the lowest number goes to studies in the field of Agriculture. 
This section described the public sector of the Portuguese public higher education market, by providing some supply and demand measures. The next section will evaluate and discuss the outcome and stability of the student allocation.

\section{Indicators of student allocation in public higher education institutions}

The analysis of supply and demand, separately, as presented in the previous section, contributes to a better understanding of the two sides of the public higher education market. However, it calls for an evaluation of student allocation across institutions and fields of study. Therefore, in this section, we compute a set of indicators which allow us to identify some of the imbalances between demand and supply. We also look at the performance of public higher education institutions regarding their competition for candidates. Finally, we compute a set of indicators that allow us to identify locus of rigidity in the public higher education system and to predict the potential impact of changes in higher education regulations on student allocation and its stability.

\section{Performance indicators}

This section aims to evaluate student allocation in the Portuguese public higher education system. Teixeira et al. (2004) have analysed the presence/absence of market mechanisms in the Portuguese higher education sector. This paper goes a step further in measuring the performance of higher education institutions concerning the matching between demand and supply, and the competition for new students. The following indicators, described below, were computed: occupation rate, first option-admitted ratio, demand pressure index, average preference rank and the grade point average of the pool of admitted students.

The occupation rate in the higher education system, that is, the proportion of available places that are filled, provides a first picture of the matching between supply and demand, namely it allows for quantifying the excess supply in the system. Numbers for the whole system show excess supply and a decreasing occupation rate. In 2003/2004, 95.4\% of places were filled, but the rate decreased to $87.5 \%$ and to $82.1 \%$ in $2004 / 2005$ and 2005 / 2006, respectively, and recovered to $88.0 \%$ in $2006 / 2007$. The occupation rate, however, hides variation across institutions and fields of study. Looking at Table 5, some salient conclusions emerge. First of all, the polytechnic subsystem shows a lower occupation rate than the university subsystem, with a difference of six percentage points between them. Precisely, six polytechnic institutions show an occupation rate below $80 \%$, while the University of Évora is the only university below that rate. The highest occupation rate within the polytechnic sector is that achieved by the Polytechnic Institute of Oporto $(98.1 \%)$, immediately followed by that of Leiria (97.2\%). In the university subsystem, the occupation rate of five institutions is above $90 \%$, three of which have full occupation: ISCTE, and the universities of Aveiro and Oporto have an occupation rate of about $99 \%$ or higher.

Considering the occupation rate across scientific areas, Health is clearly the field of study with the highest rate (more than 100\%). ${ }^{14}$ Conversely, both Humanities and

14 See note 1 , Table 5. 
Table 5 Distribution of occupation rate by institution and area of study, 2006

\begin{tabular}{|c|c|c|c|c|c|c|c|c|c|c|c|}
\hline Instit & gric & arch & natsc & lawsoc & eco & sparts & educ & hum & health & tec & Total \\
\hline Beja & 626 & 0.533 & 0.960 & 0.830 & 0.880 & 0.720 & 1.036 & & 1.057 & 0.385 & 0.762 \\
\hline PI Brag & 0.652 & 0.550 & & 0.836 & 428 & 0.500 & 0.776 & 0.640 & 1.077 & 0.364 & 0.613 \\
\hline PI Cast & 0.833 & 1.020 & & & 0.800 & & 0.875 & 0.800 & 1.047 & 0.638 & 810 \\
\hline PI Cáva & & 1.049 & & 1.000 & 1.007 & & & & & 0.694 & 0.936 \\
\hline PI Coimbra & 0.956 & 1.086 & 1.033 & 1.034 & 0.883 & 1.033 & 0.874 & 1.050 & 1.139 & 0.783 & 0.928 \\
\hline PI Gua & 0.900 & 1.040 & & 0.812 & 0.900 & 1.029 & 0.929 & 0.633 & 1.064 & 0.400 & 0.834 \\
\hline $\mathrm{P}$ & 00 & 1.056 & 1.078 & 1. & 019 & 1.024 & 0.842 & .286 & 1.100 & 0.826 & 0.972 \\
\hline PI Lisbon & & 1.000 & 1.114 & 1.045 & 0.871 & & 1.018 & & 1.081 & 0.663 & 0.874 \\
\hline PI Port & 0.763 & 0.768 & & 0.742 & 0.306 & & 0.564 & 0.694 & 1.026 & 0.208 & 0.645 \\
\hline PI Oport & & 1.000 & 1.133 & 1.029 & 1.034 & & 0.812 & 0.538 & 1.046 & 0.957 & 0.981 \\
\hline PI Sant & 1.020 & 1.000 & & 1.044 & 0.753 & 1.071 & 0.878 & & 1.100 & 0.753 & 0.941 \\
\hline $\mathrm{P}$ & 0.360 & 1.040 & & & 0.884 & 0.700 & 0.885 & 88 & 1.083 & 29 & 0.756 \\
\hline PI Tomar & 1.029 & 0.797 & & 1.029 & 0.614 & & & 0.257 & & 0.256 & 0.561 \\
\hline PI Viana & 1.061 & 1.071 & & 1.000 & 0.833 & 1.100 & 0.981 & & 1.030 & 0.690 & 0.912 \\
\hline $\mathrm{P}$ & 0.744 & 1.000 & & & 0.845 & & 0.692 & 0.633 & 1.042 & 0.445 & 0.773 \\
\hline Tot & 0.807 & 0.946 & 1.076 & 0 . & 0.845 & 0.943 & 0.850 & 0.572 & 1.055 & 0.639 & 0.845 \\
\hline ISCTE & & 1.029 & & 1.036 & 1.044 & & & 1.025 & & & .036 \\
\hline Techr & 0.750 & 1.035 & 0.855 & 0.991 & 1.018 & 0.922 & & & 1.029 & 0.846 & 0.910 \\
\hline U Alga & 0.867 & 0.758 & 0.793 & 0.946 & 0.940 & 0.633 & 0.719 & 0.790 & 0.973 & 0.713 & 0.850 \\
\hline & & 1.0 & & & 1.027 & $0.96^{\circ}$ & 1. & & & & 0.987 \\
\hline U Azores & 1.045 & 1.000 & 0.950 & 0.944 & 0.943 & & 0.550 & 0.450 & 0.933 & 0.553 & 0.838 \\
\hline U Beira & & 1.059 & 0.938 & 1.0 & 1.064 & 1.040 & 0.190 & 0.314 & 0.984 & 0.292 & 0.822 \\
\hline U C & 0.800 & 1.033 & 0.881 & 1. & 1.022 & 1.011 & 0.792 & 0.595 & 1.018 & 0.637 & 0.885 \\
\hline U Évora & 0.513 & 0.873 & 0.611 & 1.030 & 1.078 & 1.040 & 1.033 & 0.413 & 1.066 & 0.389 & 0.792 \\
\hline $\mathrm{UL}$ & & 1.015 & 0.745 & 1.0 & & 1.000 & 1.011 & 0.463 & 1.020 & 0.918 & 0.848 \\
\hline U M & & 0.767 & 0.340 & 1.018 & 1.036 & 0.900 & 0.800 & 1.040 & 1.000 & 0.658 & 0.835 \\
\hline U Minho & & 1.020 & 0.610 & 1.028 & 1.052 & & 1.036 & 0.983 & 1.021 & 0.948 & 0.948 \\
\hline U I & 0 & 0.709 & 0.839 & 0.819 & 1.019 & 00 & & 0.756 & 1.000 & 0.898 & 0.881 \\
\hline U Oporto & 0.917 & 1.013 & 0.938 & 1.028 & 1.003 & 1.000 & 1.127 & 0.989 & 1.018 & 0.986 & .996 \\
\hline UTAD & 0.790 & 1.040 & 1.102 & 0.985 & 1.047 & 0.937 & 0.470 & 0.244 & 1.028 & 0.524 & 0.845 \\
\hline Total University & 0.777 & 0.983 & 0.832 & 1.001 & 1.018 & 0.966 & 0.830 & 0.687 & 1.012 & 0.829 & 0.904 \\
\hline Total & 0.794 & 0.969 & 0.849 & 0.979 & 0.930 & 0.958 & 0.843 & 0.672 & 1.034 & 0.747 & 0.880 \\
\hline
\end{tabular}

Notes: 1 . Occupancy rates can be above 1 . In some specific situations, institutions may admit more students than the available places. For instance, when there is a group of students with the same characteristics regarding the requirements for a given study, all of them should be admitted, even if this implies the creation of additional places

2. The polytechnic subsystem includes Escolas Superiores as well, although occupation rates for each of those schools are not shown in the table. However, occupation rates for the whole polytechnic subsystem and for the higher education system were obtained using those schools

3. See footnotes 2 and 5, Table 1

Technologies present occupation rates below 75\%. Within the Technologies, only five institutions have an occupation rate of at least 95\%: ISCTE, the Universities of Aveiro, Minho and Oporto and the Polytechnic Institute of Oporto. 
The analysis of the occupation rate, however, does not indicate how satisfied allocated students are. The fact that students rank a maximum of six alternative study/institution pairs allows us to know what their (conditional) best choices are. Table 6 shows the proportion of admitted students to the first option by higher education institution, which is a proxy for students' happiness. The proportion for the whole system is about $66 \%$, which hides differences between subsystems, that is, a proportion of about $69 \%$ in the university subsystem contrasts with a rate of about $61 \%$ in polytechnics. The highest proportion of

Table 6 First option-admitted ratio by institution and area of study, 2006

\begin{tabular}{|c|c|c|c|c|c|c|c|c|c|c|c|}
\hline Instit & agric & $\operatorname{arch}$ & natsc & lawsoc & eco & sparts & educ & hum & health & tec & Total \\
\hline I Beja & 0.472 & 1.000 & 0.500 & 0.628 & 0.909 & 0.111 & 0.561 & & 351 & 0.857 & 0.583 \\
\hline PI Bragança & 0.403 & 0.545 & & 0.613 & 0.467 & 0.367 & 0.560 & 0.875 & 0.354 & 0.539 & 0.489 \\
\hline PI Castelo Branco & 0.486 & 0.686 & & 0.648 & 0.635 & & 0.486 & 0.550 & 16 & 0.573 & 0.587 \\
\hline PI Cávado\&Ave & & 0.588 & & 0.800 & 0.779 & & & & & 0.508 & 0.675 \\
\hline PI Coi & 0.413 & 0.645 & 0.065 & 0.600 & 0.558 & 0.355 & 0.711 & 0.810 & .307 & 0.794 & 0.580 \\
\hline PI Guarda & 0.407 & 0.385 & & 0.458 & 0.604 & 0.333 & 0.554 & 0.684 & 0.359 & 0.714 & 0.492 \\
\hline - & 0.370 & 0.550 & 0.608 & 0.622 & 0.813 & 0.862 & 0.513 & 0.500 & 0.455 & 0.762 & 0.647 \\
\hline PI Lisbon & & 0.818 & 0.205 & 0.687 & 0.652 & & 0.722 & & 0.351 & 0.786 & 0.622 \\
\hline PI Opc & & 0.900 & 0.039 & 0.719 & 0.841 & & 0.696 & 1.086 & 8 & 64 & 0.698 \\
\hline PI Portalegre & 0.508 & 0.547 & & 0.568 & 0.773 & & 0.387 & 0.580 & 0.329 & 1.000 & 0.535 \\
\hline 2. & 0.843 & 0.500 & & 0.596 & 0.766 & 0.448 & 0.835 & & 0.364 & 13 & 0.577 \\
\hline PI Setúbal & 0.667 & 0.615 & & 0.548 & 0.693 & 0.357 & 0.783 & 1.000 & 0.610 & 0.722 & 0.667 \\
\hline PI Tomar & 0.472 & 0.628 & & 0.583 & 0.519 & & & 0.889 & & 1.000 & 0.638 \\
\hline PI Viana do Castelo & 0.486 & 0.587 & & 0.700 & 0.782 & 0.576 & 0.583 & & 0.559 & 0.552 & 0.585 \\
\hline PI Viseu & 0.482 & 0.733 & & 0 & 0.686 & & 0.594 & 0.368 & 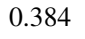 & 73 & 0.620 \\
\hline Total Polytechnic & 0.472 & 0.634 & 0.343 & 0.627 & 0.697 & 0.505 & 0.631 & 0.718 & 0.446 & 0.732 & 0.608 \\
\hline ISCTE & & 0.250 & & 0.575 & 0.666 & & & 0.583 & & 91 & 0.644 \\
\hline Technic & 0.641 & 0.668 & 0.606 & 0.465 & 0.501 & 0.838 & & & 42 & 0.935 & 0.723 \\
\hline U Algarve & 0.295 & 0.714 & 0.478 & 0.671 & 0.753 & 0.895 & 0.680 & 0.807 & 0.397 & 0.893 & 0.655 \\
\hline $\mathrm{U} A v$ & 0.489 & 0.605 & 0.447 & 0.586 & 0.584 & 1.207 & 0.675 & 0.592 & 40 & 67 & 0.630 \\
\hline U Azores & 0.478 & 0.680 & 0.684 & 0.798 & 0.924 & & 0.955 & 0.333 & 0.610 & 0.851 & 0.756 \\
\hline U Beira & & 0.433 & 0.221 & 0.469 & 0.812 & 0.644 & 1.000 & 0.318 & 53 & 86 & 0.486 \\
\hline U Coimbra & 63 & 0.742 & 0.486 & 9 & 69 & 0.677 & 0.284 & 0.675 & 0.536 & 0.821 & 0.679 \\
\hline U Évora & 0.732 & 0.417 & 0.441 & 0.594 & 0.835 & 0.462 & 0.629 & 0.848 & 0.420 & 0.838 & 0.588 \\
\hline U Lisbon & & 0.640 & 0.708 & 0.723 & & 0.650 & 0.484 & 0.746 & 0.518 & 0.671 & 0.660 \\
\hline U Madeira & & 0.957 & 0.588 & 0.672 & 0.789 & 0.667 & 0.604 & 0.923 & 0.603 & 0.962 & 0.744 \\
\hline U Minho & & 0.627 & 0.651 & 0.738 & 0.895 & & 0.774 & 0.606 & 0.677 & 0.645 & 0.691 \\
\hline U Nova & 0.706 & 0.923 & 0.419 & 1.000 & 0.943 & 0.950 & & 0.740 & 0.730 & 0.776 & 0.811 \\
\hline U Oporto & 0.327 & 0.845 & 0.510 & 0.837 & 1.082 & 1.045 & 0.210 & 0.629 & 0.655 & 0.858 & 0.753 \\
\hline UTAD & 0.442 & 0.500 & 0.345 & 0.616 & 0.910 & 0.618 & 0.638 & 0.545 & 0.622 & 0.736 & 0.581 \\
\hline Total University & 0.510 & 0.656 & 0.517 & 0.706 & 0.768 & 0.771 & 0.575 & 0.676 & 0.563 & 0.815 & 0.687 \\
\hline Total & 0.488 & 0.648 & 0.502 & $0.6 / 8$ & 0.735 & 0.673 & 0.610 & 0.681 & 0.504 & 0.784 & 0.656 \\
\hline
\end{tabular}

Note: 1. The first option-admitted ratio is computed as the total number of places taken by students who placed it as first option to the total number of places filled

2. See footnotes 2 and 5 , Table 1 
students admitted in their first option is achieved in the field of Technology for both subsystems. For the other fields of study there is considerable variation across institutions.

A deeper analysis of the final allocation of students in the Portuguese higher education market requires, however, additional measures. Firstly, an indicator of the demand pressure has been computed, $r_{i}$, which is the ratio of the number of hits each institution $i$ gets $\left(h_{i}\right)$ to the number of places in that institution $\left(p_{i}\right)$. Its computation is based on students' revealed preferences, and is given by:

$$
r_{i}=\frac{h_{i}}{p_{i}} .
$$

It is important to recall that hits are the total number of times an institution/study is chosen. It can be seen as an indicator of the students' interest in the study programme, and therefore a measure for the potential demand for that study, or its ability to attract new students.

The demand pressure index and the rank positions according to this are shown in the first two columns of Table 7. Within the university sector, University of Aveiro and ISCTE are the institutions that better perform regarding the demand pressure, contrasting with the Universities of the Azores, Lisbon, Madeira and the Algarve that belong to the group with the worst performance. This may reflect the remoteness of the universities of the Azores, Madeira and the Algarve. Polytechnics of Lisbon and Oporto show a high ability to attract students, whereas those of Tomar, Bragança and Beja are of interest to far fewer students.

From the institutions' standpoint, it is obviously important to fill the places available. It allows them to more efficiently use their capacity, and qualifies them for more public funding. But the quality of their student body also has a non-negligible role in the position of a higher education institution in the market. High performing students are the best inputs that an institution may look for, as they might start a virtuous cycle of high standards in education and stimulate research.

The stock of human capital at entrance of the pool of admitted students can work as an indicator of student body quality, and can be proxied by the mean of their grade point average. This performance index has been called $\bar{G}_{i}$. Although it proxies the quality of the initial stock of human capital, the fact that it depends on study programme requirements is an obvious limitation, which should be taken into account when analysing the data. According to Table 7, the University of Oporto is the institution with the best pool of students, as shown by an average entrance grade of 150/200 points.

So far, we have discussed the indicators showing how they vary across higher education institutions. But there are other dimensions to be analysed. In particular, there is some variability in those indices according to the field of study. Table 8 shows the above presented indices computed for each field of study.

Health studies present by far the highest number of hits per place $\left(r_{i}\right)$, about 10.6, revealing the highest demand pressure in the system. Humanities, on the contrary, present the lowest tension on the demand side (that is, 3.5). The highest average grade among the students accepted for a given study $\left(\bar{G}_{i}\right)$ belongs to Health Studies (156/200), and the lowest to Education Studies (less than 130/200).

An important conclusion from the previous section was that of an existing excess of capacity in the system. Excess capacity is the consequence of demographic trends and large investments in the public sector during the 1990's (OECD 2006). This situation implies an increasing competition between higher education institutions for students. 
Table 7 Indicators on market (dis)equilibrium, 2006

\begin{tabular}{|c|c|c|c|c|}
\hline Institution & $r_{i}$ & $\bar{G}_{i}$ & $s_{i}$ & $w_{i}$ \\
\hline PI Beja & $4.00(13)$ & $128(13)$ & $0.63(12)$ & $0.56(11)$ \\
\hline PI Bragança & $3.73(14)$ & $129(12)$ & $0.50(14)$ & $0.70(15)$ \\
\hline PI Castelo Branco & $5.51(6)$ & $132(7)$ & $0.90(9)$ & $0.52(10)$ \\
\hline PI Cávado\&Ave & $6.21(3)$ & $134(3)$ & $1.22(3)$ & $0.37(2)$ \\
\hline PI Coimbra & $6.03(4)$ & $132(7)$ & $0.93(8)$ & $0.46(4)$ \\
\hline PI Guarda & $5.39(7)$ & $128(13)$ & $0.64(11)$ & $0.59(12)$ \\
\hline PI Leiria & $5.39(7)$ & $134(3)$ & $1.07(5)$ & $0.37(2)$ \\
\hline PI Lisbon & $6.96(1)$ & $142(1)$ & $1.45(2)$ & $0.46(4)$ \\
\hline PI Oporto & $6.69(2)$ & $139(2)$ & $1.54(1)$ & $0.32(1)$ \\
\hline PI Portalegre & $4.45(11)$ & $131(10)$ & $0.52(13)$ & $0.66(14)$ \\
\hline PI Santarém & $5.70(5)$ & $132(7)$ & $1.00(6)$ & $0.46(4)$ \\
\hline PI Setúbal & $4.68(9)$ & $133(5)$ & $1.10(4)$ & $0.50(8)$ \\
\hline PI Tomar & $2.57(15)$ & $128(13)$ & $0.39(15)$ & $0.64(13)$ \\
\hline PI Viana do Castelo & $4.62(10)$ & $133(5)$ & $0.95(7)$ & $0.47(7)$ \\
\hline PI Viseu & $4.22(12)$ & $130(11)$ & $0.76(10)$ & $0.52(9)$ \\
\hline ISCTE & $7.75(2)$ & $141(9)$ & $1.72(2)$ & $0.33(3)$ \\
\hline Technical U & $5.70(7)$ & $146(4)$ & $1.26(7)$ & $0.34(4)$ \\
\hline U Algarve & $4.78(11)$ & $135(14)$ & $1.00(10)$ & $0.44(10)$ \\
\hline U Aveiro & $8.05(1)$ & $141(9)$ & $1.59(4)$ & $0.38(7)$ \\
\hline U Azores & $3.95(14)$ & $138(11)$ & $0.96(12)$ & $0.36(6)$ \\
\hline U Beira Interior & $6.66(3)$ & $142(6)$ & $1.16(9)$ & $0.60(14)$ \\
\hline U Coimbra & $5.98(4)$ & 146 (4) & $1.19(8)$ & $0.40(9)$ \\
\hline U Évora & $5.57(8)$ & $138(11)$ & $0.95(13)$ & 0.53 \\
\hline U Lisbon & $3.96(13)$ & $147(2)$ & $0.95(13)$ & $0.44(10)$ \\
\hline U Madeira & $4.46(12)$ & $142(6)$ & $1.66(3)$ & $0.38(7)$ \\
\hline U Minho & $5.46(9)$ & $142(6)$ & $1.30(6)$ & $0.35(5)$ \\
\hline U Nova & $5.85(5)$ & 147 (2) & $1.44(5)$ & $0.29(2)$ \\
\hline U Oporto & $5.82(6)$ & $154(1)$ & 1.77 (1) & $0.25(1)$ \\
\hline UTAD & $5.45(10)$ & 137 (13) & $0.97(11)$ & $0.51(12)$ \\
\hline
\end{tabular}

Note: 1 . For each indicator we present its value, as well as the rank of the institution within each subsystem (in brackets)

2. See footnote 5 , Table 1

If more flexibility was allowed in the higher education system, we would expect programmes facing an insufficient demand to adjust by reducing their tuition fees, or, if keeping the price constant, downsizing those programmes or closing them down. The reverse would be expected for programmes facing a higher demand relative to the number of places.

Under some constraints imposed by law as described in section "The Portuguese higher education system: institutions and regulation", there is price differentiation across institutions, and, in some cases (e.g. University of Lisbon), different amounts apply to different study programmes (MCTES 2006). However, the variation interval is fairly small and might be not enough to guarantee that changes in prices were needed to assure the equilibrium between demand and supply. 
Table 8 Performance indices per programme area in 2006

\begin{tabular}{lclll}
\hline Area & $r_{i}$ & $\bar{G}_{i}$ & $s_{i}$ & $w_{i}$ \\
\hline Agriculture & $4.04(8)$ & $132(5)$ & $0.58(10)$ & $0.62(10)$ \\
Architecture & $5.73(3)$ & $145(2)$ & $1.24(3)$ & $0.40(3)$ \\
Natural Sciences & $5.20(5)$ & $141(3)$ & $0.71(8)$ & $0.59(9)$ \\
Law and Social Sciences & $6.95(2)$ & $136(4)$ & $1.44(2)$ & $0.38(2)$ \\
Economics & $5.47(4)$ & $131(7)$ & $1.09(4)$ & $0.37(1)$ \\
Sports and Arts & $4.86(6)$ & $131(7)$ & $1.06(5)$ & $0.41(4)$ \\
Education & $4.03(9)$ & $129(10)$ & $0.84(6)$ & $0.50(6)$ \\
Humanities & $3.53(10)$ & $132(5)$ & $0.67(9)$ & $0.54(7)$ \\
Health & $10.58(1)$ & $156(1)$ & $2.15(1)$ & $0.55(8)$ \\
Technology & $4.12(7)$ & $131(7)$ & $0.75(7)$ & $0.49(5)$ \\
Total & 5.63 & 136.47 & 1.09 & 0.48 \\
\hline
\end{tabular}

Notes: See notes 1 and 2, Table 1

Concerning quantity, our indicators suggest that there is a high rigidity in the system as well as within the institutions themselves, which may hinder the adjustment to the changing conditions in the demand side of the market. In 2006, 234 programmes (i.e., 24\%), representing 6,503 places (i.e., 14\%) had less than 20 students admitted. Confronted with rigidity, the MCTES recently decided to stop financing study programmes with less than 20 students admitted. Institutions can continue to offer them, but at their own expenses. If that decision is fully implemented, Polytechnics, the most affected institutions, would lose 3,372 places, that is, $18 \%$ of the places available in that subsystem.

Another via of adjustment available is mergers between institutions, which could result in the redefinition of the higher education network and a better matching between demand and supply. A good example is the announced merger between the University of Lisbon and the Polytechnic of Lisbon, which together take 5,530 places, representing a $12 \%$ market share in public higher education, in the school year 2006/2007. ${ }^{15}$

The indicators presented in this section allowed for an identification and characterization of the performance and imbalances in the Portuguese public higher education system. In the next section, we go a step further by presenting indicators of strength and weakness that may help predict and inform future adjustments of the system.

\section{Adjustment indicators}

Using student revealed preferences we compute strength and weakness indicators. A major advantage of these indicators is that they will allow us to identify locus of rigidity in the public higher education system and to predict the potential impact of changes in higher education regulations on student allocation and its stability.

\footnotetext{
${ }^{15}$ If we recomputed the diversity index for the University of Lisbon, considering the intended merger, we would find that it increased from 0.785 to 0.863 , taking into account computations based on the places available in each field of study.
} 
The strength measure, $s_{i}$, is defined as

$$
s_{i}=\frac{f o_{i}}{p_{i}},
$$

where $f o_{i}$ is the total number of students choosing institution $i$ as first option. The strength index can be interpreted as the proportion of places that are certain in the allocation of students to higher education institutions, since the first option reveals students' first-best. Given the constraints, specifically their grades in secondary education and the admission exams, students' decisions are the result of an optimization process, and, as such, are optimal. Under this assumption, first choices can be taken as absolute preferences that will not be changed. If $s_{i}>1$, then all places offered are assuredly filled. This means that institutions would be able to expand their capacity if they are allowed to increase the number of places and admit more students. The opposite occurs when $s_{i}<1$. That is, an institution might not be filling all places, which can be seen as a first indicator of institutional weakness.

From Table 7, it appears that polytechnics perform worse than universities regarding the strength indicator. The University of Oporto shows the highest value for the strength measure (1.77). The immediate implication is that without supply constraints, the University of Oporto could increase the number of places by $77 \%$ without excess supply. The Universities of Lisbon and Évora, on the contrary, are the institutions with the lowest strength value in the university subsystem. The fact that the strength index is below 1 for both implies that the end of the numerus clausus regulation could cause them to lose students. In the Polytechnic subsystem, the institution in Oporto is once again the strongest one, as shown by the value of the index (1.54), while the Polytechnic Institute of Tomar has the smallest value of the overall system (0.49). This exercise makes it possible to get a first picture of the effects of the end of numerus clausus, despite some limitations that should, however, be kept in mind. Namely, numerus clausus is among the constraints that students take into account when applying to higher education, and therefore it cannot be taken as guaranteed that their choice set composition would be the same if that constraint did not apply.

We also compute a weakness index, $w_{i}$, defined as

$$
w_{i}=\frac{p_{i}-F O_{i}}{p_{i}},
$$

where $F O_{i}$ is the total number of first options among the admissions to higher education institution $i$. The index informs on the proportion of places filled with second-best alternatives, that is, the proportion of students that might be lost to other institutions in the case of the numerus clausus distribution changing. The index is bound between 0 and 1 . The lower the value, the lower the weakness in the case of competing courses in other institutions being allowed to increase numerus clausus.

Table 7 summarizes the values for the weakness index by higher education institution. It shows that, similar to what happens in the strength index analysis, the University of Oporto is the institution with the smallest proportion of students that potentially can be lost. In the polytechnic subsystem, the Polytechnic Institute of Bragança is the most fragile institution, which in the free access (no numerus clausus) scenario could lose $70 \%$ of its potential students (measured by places).

Regarding the strength and weakness indices by field study, Health is the area of studies with the highest strength (2.15), whereas the lowest belongs to Agriculture (0.58). 
Economic Studies show the lowest weakness level (0.37). Agriculture-type studies get the highest value for the weakness index (0.62), meaning that about $62 \%$ of the places are filled by non-first options.

We argue that strength and weakness indicators are measures of the degree of mismatching between demand and supply, which can be used in predicting the impact of changes in higher education regulations on market equilibrium and stability. For example, the value of the strength indicator for the whole system, $s_{i}$, is 1.09 (see Table 8), which indicates that, in 2006, there were more candidates than vacancies. However, when we look at the values by field of study or by institution (see Table 7) we find that there are significant imbalances in the system in the sense that many candidates are not placed in their first option. In fact, out of the 29 institutions considered in our analysis, 16 have a strength index above 1 (see Table 7), that is, those institutions could increase their numerus clausus in order to improve the match between demand and supply. On the other hand, 10 institutions, among the 29 analysed, show a weakness indicator above 0.5 , that is, in those institutions more than $50 \%$ of the vacancies were potentially filled by candidates that did not rank the institution in their first option. In this case, if higher education institutions were free to set their numerus clausus, those institutions could loose a significant portion of their students.

Neverthless, these results do not imply that regulations, such as the numerus clausus, should be eliminated, but rather that some changes in the regulations may be due. For example, the results from Table 8, namely, $s_{i}$ of 2.15 for Health, would recommend an increase in the numerus clausus in that field of study. That is, fields of study and institutions with higher values for strength and lower values for weakness indices could enhance their market share if their supply was allowed to adjust to demand.

\section{Concluding remarks}

This paper contributes to a better understanding of the student allocation process in the Portuguese public higher education system. It aims at evaluating student allocation by providing a set of demand and supply indicators, and at quantifying the mismatching between demand and supply.

Our analysis confirms that although total demand and supply in the Portuguese public higher education system are quite close to each other, this hides substantial variation across institutions and fields of study. In fact, the occupation rate for the system as a whole has been systematically below full-capacity over the period under analysis; however, five institutions had full or nearly full occupation, whereas seven institutions did not fill one fifth of the places. On average, universities show higher values for the first option-admitted students ratio than Polytechnics. There is also substantial variability of the demand pressure across institutions and of the quality of the pool of admitted students. It is interesting to note that the institutions which perform the best regarding demand pressure, do not always show good performance concerning the quality of the student body they get.

When looking at the indicators of adjustment, that is, the strength and weakness indicators, a similar and interesting pattern emerges, with institutions and fields of study differing in terms of degree of demand-supply mismatching. The strength indicator shows that there is a significant proportion of students that are not allocated to their first option. More than a half of the institutions can increase the number of vacancies offered and then contribute to a better demand-supply match. Results for the weakness index indicate that if 
supply in the higher education system was allowed to change, several institutions could lose a significant portion of their students.

In the context of the current higher education system reform taking place in Portugal, our results may inform new policies. The strength and weakness indicators provide relevant information and guidance to policymakers regarding the adjustment of the higher education network. In particular, they suggest the expansion of some institutions and fields of study and the contraction of others via resetting the numerus clausus distribution. Furthermore, this type of analysis provides higher education institutions with information they need to inform their decisions on the allocation of numerus clausus across study porgrammes. It should be stressed, however, that the information conveyed by these indicators should be complemented with information from other sources such as graduate employability.

Summing up, institutions and fields of study show very different performances when evaluated by the above indicators based on candidates' revealed preferences. Although there is no tradition of rankings of the Portuguese higher education institutions, our results suggest that students do rank institutions when making their choices, which is reflected on performance indicators and on its variation across institutions and fields of study. Institutional rankings based on students' revealed preferences, like the one proposed by Avery et al. (2004), may benefit from indicators such as the strength and weakness indices presented in this paper. However, the ranking of institutions using candidates' revealed preferences requires data at the individual level, including additional information on residence, high school performance, socio-economic background, among others, which allow for a better understanding of the individual decision making process when ordering higher education institutions. Such ranking should also be complemented with information on the institutions' performance, as for example faculty quality, scientific output, graduates' employability. This issue deserves, however, a much more detailed and careful analysis, and should therefore be the subject of further research.

Acknowledgements We wish to thank Alberto Amaral for his comments on a previous version of this paper. We also benefited from comments and suggestions from participants of the NIPE Seminar, Universidade do Minho, Braga, Portugal.

\section{References}

Avery, C., Glickman, M., Hoxby, C., \& Metrick, A. (2004). A revealed preference ranking of US colleges and universities. NBER Working Paper 10803.

Brose, U. (2003). Regional diversity of temporary wetland carabid beetle communities: a matter of landscape features or cultivation intensity? Agriculture, Ecosystems \& Environment, 98(1-3), 163-167.

Geiger, R. (2004). Market coordination of higher education: The United States. In P. Teixeira, B. Jongbloed, D. Dill, \& A. Amaral (Eds.), Markets in higher education: Rhetoric or reality. Dordrecht: Kluwer.

Huisman, J., Kaiser, F., \& Vossensteyn, H. (2000). Floating foundations of higher education policy. Higher Education Quarterly, 54(3), 217-238.

Jongbloed, B. (2003). Marketisation in higher education, Clark's triangle and the essential ingredients of markets. Higher Education Quarterly, 57(2), 110-135.

MCTES, Ministério da Ciência, da Tecnologia e do Ensino Superior. (2006). Reviews of National policies for education: Tertiary education in Portugal. Background report. Available at: http://www.mctes.pt/ docs/ficheiros/EDU_EC_2006_26.pdf

OCES, Observatório da Ciência e do Ensino Superior. (2007). Evolução do Número de Inscritos no Ensino Superior por Distrito e NUTSII, 1997/98-2005/06. Available at: http://www.oces.mctes.pt/docs/ficheiros/ Inscritos1998_2005.pdf 
OECD, Organization for Economic Co-operation and Development. (2006). Reviews of National policies for education: Tertiary education in Portugal. Examiner's report. Available at: http://www.mctes.pt/ docs/ficheiros/OCDE_Relatorio_124_paginas_.pdf

Portela, M., Areal, N., Sá, C., Alexandre, F., Cerejeira, J., Carvalho, A., \& Rodrigues, A. (2007). Regulation and marketisation in the Portuguese higher education system. NIPE Working Paper 11/2007.

Rhodes, G., \& Slaughter, S. (2004). Academic capitalism in the new economy: Challenges and choices. American Academic, 1(1), 37-59.

Sá, C. (2006). Higher education choice in the Netherlands: The economics of where to go. Thela Thesis: Amsterdam.

Sá, C., Florax, R. J. G. M., \& Rietveld, P. (2004). Determinants of the regional demand for higher education in the Netherlands: A gravity model approach. Regional Studies, 38(4), 373-390.

Simão, J. V., Santos, S. M., \& Costa, A. A. (2004). Ensino Superior: uma Visão para a Próxima Década. Lisbon: Gradiva.

Teixeira, P., Jongbloed, B., Dill, D., \& Amaral, A. (Eds.). (2004). Markets in higher education: Rhetoric or reality. Dordrecht: Kluwer.

Teixeira, P., Rosa, M. J., \& Amaral, A. (2004). Is there a higher education market in Portugal? In P. Teixeira, B. Jongbloed, D. Dill, \& A. Amaral (Eds.), Markets in higher education: Rhetoric or reality. Dordrecht: Kluwer.

van der Ploeg, F., \& Veugelers, R. (2007). Higher education reform and the renewed Lisbon strategy: Role of member states and the European Commission. CESifo Working Paper Series 1901. 